\title{
Demographic, behavioral, and cardiovascular disease risk factors in the Saudi population: results from the Prospective Urban Rural Epidemiology study (PURE-Saudi)
}

Khalid F. Alhabib ${ }^{1 *}$ (D), Mohammed A. Batais², Turky H. Almigbal ${ }^{2}$, Mostafa Q. Alshamiri ${ }^{1}$, Hani Altaradi ${ }^{1}$, Sumathy Rangarajan ${ }^{3}$ and Salim Yusuf ${ }^{3}$

\begin{abstract}
Background: Cardiovascular disease (CVD) is the major cause of death in Saudi Arabia. We aimed to assess associated demographic, behavioral, and CVD risk factors as part of the Prospective Urban Rural Epidemiology (PURE) study.

Methods: PURE is a global cohort study of adults ages $35-70$ years in 20 countries. PURE-Saudi study participants were recruited from 19 urban and 6 rural communities randomly selected from the Central province (Riyadh and Alkharj) between February 2012 and January 2015. Data were stratified by age, sex, and urban vs rural and summarized as means and standard deviations for continuous variables and as numbers and percentages for categorical variables. Proportions and means were compared between men and women, among age groups, and between urban and rural areas, using Chi-square test and t-tests, respectively.

Results: The PURE-Saudi study enrolled 2047 participants (mean age, $46.5 \pm 9.12$ years; $43.1 \%$ women; $24.5 \%$ rural). Overall, 69.4\% had low physical activity, 49.6\% obesity, 34.4\% unhealthy diet, 32.1\% dyslipidemia, 30.3\% hypertension, and $25.1 \%$ diabetes. In addition, $12.2 \%$ were current smokers, $15.4 \%$ self-reported feeling sad, $16.9 \%$ had a history of periods of stress, $6.8 \%$ had permanent stress, $1 \%$ had a history of stroke, $0.6 \%$ had heart failure, and $2.5 \%$ had coronary heart disease (CHD). Compared to women, men were more likely to be current smokers and have diabetes and a history of CHD. Women were more likely to be obese, have central obesity, self-report sadness, experience stress, feel permanent stress, and have low education. Compared to participants in urban areas, those in rural areas had higher rates of diabetes, obesity, and hypertension, and lower rates of unhealthy diet, self-reported sadness, stress (several periods), and permanent stress. Compared to middle-aged and older individuals, younger participants more commonly reported an unhealthy diet, permanent stress, and feeling sad.

(Continued on next page)
\end{abstract}

* Correspondence: khalidalhabib13@hotmail.com

'Department of Cardiac Sciences, King Fahad Cardiac Center, College of

Medicine, King Saud University, Riyadh, Saudi Arabia

Full list of author information is available at the end of the article

(c) The Author(s). 2020 Open Access This article is licensed under a Creative Commons Attribution 4.0 International License, which permits use, sharing, adaptation, distribution and reproduction in any medium or format, as long as you give appropriate credit to the original author(s) and the source, provide a link to the Creative Commons licence, and indicate if changes were made. The images or other third party material in this article are included in the article's Creative Commons licence, unless indicated otherwise in a credit line to the material. If material is not included in the article's Creative Commons licence and your intended use is not permitted by statutory regulation or exceeds the permitted use, you will need to obtain permission directly from the copyright holder. To view a copy of this licence, visit http://creativecommons.org/licenses/by/4.0/. The Creative Commons Public Domain Dedication waiver (http://creativecommons.org/publicdomain/zero/1.0/) applies to the data made available in this article, unless otherwise stated in a credit line to the data. 
(Continued from previous page)

Conclusion: These results of the PURE-Saudi study revealed a high prevalence of unhealthy lifestyle and CVD risk factors in the adult Saudi population, with higher rates in rural vs urban areas. National public awareness programs and multi-faceted healthcare policy changes are urgently needed to reduce the future burden of CVD risk and mortality.

Keywords: Demographics, Prevalence, Risk factors, Cardiovascular disease, Urban, Rural, Saudi Arabia

\section{Background}

Cardiovascular disease (CVD) is the leading cause of mortality worldwide, contributing to $31 \%$ of all deaths [1]. CVD is also becoming a major health concern in the Gulf Council Countries, including Saudi Arabia, where it is estimated that CVD accounts for more than $45 \%$ of all deaths $[1,2]$. The most common CVD risk factors identified in the INTERHEART and INTERSTROKE studies were hypertension, diabetes, dyslipidemia, obesity, smoking, low physical activity, poor diet, and alcohol consumption $[3,4]$. In the Gulf countries, lifestyle has changed dramatically because of rapid urbanization, with an increase in poor diet and the adoption of a sedentary lifestyle. Consequently, rates of CVD risk factors and chronic non-communicable diseases in the Gulf population are also high [2, 5-32].

The aim of the Prospective Urban Rural Epidemiology (PURE) cohort study is to collect data on social, environmental, and individual CVD risk factors and chronic diseases in high-, middle-, and low-income countries [33]. Saudi Arabia has been classified as a high-income country and joined the global PURE study in 2012. The current PURE Saudi report focuses mainly on assessing the demographics, unhealthy lifestyle, and prevalence of CVD risk factors, stratified by age, sex, and place of residence (urban vs rural). Given the relatively small sample size at this stage, we have reported only the absolute number of cases diagnosed with cancer, myocardial infarction, stroke, heart failure, and death during a median (interquartile range [IQR]) follow-up of 3.4 (3.2-6.1) years.

\section{Methods}

\section{Study design and participants}

The study design, methods (including sampling, information gathered, and follow-up strategy), and participant characteristics of the PURE study have been published previously [33-36]. Briefly, the study included adults ages 35 to 70 years from 367 urban and 302 rural communities in 20 countries. Households were eligible if one or more members was age 35 to 70 years and the household members intended to stay at that address for a further 4 years. Risk factors and medical history were documented, and a physical examination was performed on participants who provided written informed consent. Details of sampling, information gathered, and follow-up strategy have been previously reported [34, 35].

\section{Procedures}

Data regarding demographic factors, socioeconomic status, medical history, health behaviors (e.g., smoking, physical activity, diet, alcohol intake), and household members living with participants were collected by using standardized questionnaires. Low education was defined as no education, primary education only, or unknown educational level. Diet quality was determined based on the Alternative Healthy Eating Index, with scores ranging from 6 to 70 and higher scores indicating more healthful eating [37, 38]. A score of less than 31 was taken as indicating an unhealthful diet. In addition, we collected information regarding psychosocial factors (feeling "blue" and general stress) and other CVD risk factors such as hypertension, diabetes, and obesity, as described in the INTERHEART study [3, 4, 39]. We defined stress as reporting stress over several periods and/ or having permanent stress. Operationally, stress is defined as feeling irritable or anxious or having sleeping difficulties as a result of conditions at work or at home. We categorized stress as follows: $1=$ none or little; $2=$ moderate; and 3 = high-severe.

The questionnaire also asked about anthropometric measures, including weight, height, body mass index (BMI, $\mathrm{kg} / \mathrm{m}^{2}$ ), waist circumference, and blood pressure. Physical activity was measured using the International Physical Activity Questionnaire and was categorized according to the metabolic equivalent of task (MET) per min per week as low activity at 600 or fewer MET min per week [40].

Participants were considered to have diabetes if they were previously diagnosed by a physician, had a fasting plasma glucose $\geq 126 \mathrm{mg} / \mathrm{dl}(7.0 \mathrm{mmol} / \mathrm{l})$, or were being treated with glucose-lowering medication. Those with history of hypertension, current use of antihypertensive medication, and/or blood pressure $\geq 140$ (systolic) or $\geq 90$ (diastolic) $\mathrm{mmHg}$ were considered to have hypertension. All respondents were asked whether they had a medical diagnosis of hypertension (awareness) and whether they were receiving antihypertensive medication (treatment). Hypertension control was defined as the proportion of participants with an average systolic/diastolic blood pressure of $<140 / 90 \mathrm{mmHg}$. Following a standardized procedure provided for all sites, blood pressure was measured two times using an Omron digital blood pressure device (Omron HEM-757; Omron Healthcare, Kyoto, Japan) at 
the right arm, with the participant in a sitting position. A total cholesterol level $>5.2 \mathrm{mmol} / \mathrm{l}(201 \mathrm{mg} / \mathrm{dl})$ was considered to be elevated. Major CVD (myocardial infarction or angina, stroke, or heart failure) was the main clinical outcome included in the analyses based on participant self-reported responses. We assessed CVD risk using the INTERHEART Risk score, which is a validated score for quantifying risk-factor burden without the use of laboratory testing. Scores range from 0 to 48 , with higher scores indicating greater risk-factor burden.

\section{PURE Saudi}

Recruitment of Saudi individuals for the PURE study was carried out between February 2012 and January 2015. Nineteen urban and six rural communities were enrolled from the city of Riyadh and Alkharj (Central province). Urban communities involved were defined according to the governmental geographic distribution of the districts, whereas rural communities were defined as those regions located at least $50 \mathrm{~km}$ from the center of Riyadh. For cultural acceptance, the study team met the participants in the primary healthcare centers (PHCCs) in each community. The database of each PHCC was screened, and eligible candidates were randomly invited to participate in the study through a call and/or short text message to their mobile phones. A target number of at least 50 participants was required to be enrolled through each PHCC. All participants were encouraged to invite their eligible family members living in the same household. All blood samples were shipped to the laboratory in the King Khalid University Hospital at King Saud University, Riyadh. Results of the blood tests were returned to the treating physicians at the PHCC for further assessment and management.

During the follow-up period, the study team placed a telephone call at 18 months after the baseline recruitment to remind participants about their upcoming follow-up at 3, 6, and 9 years. During a median (IQR) follow-up of 3.4 (3.2-6.1) years, the study team recorded death, cancer, myocardial infarction, stroke, and heart failure based on self-reports from the participant or a family member. Incidence rates were then calculated, taking into account the duration of follow-up and time to the corresponding events.

\section{Statistical analysis}

The total number of participants recruited for this study was determined using convenience sampling based on real-life acceptance rates from the community, with the aim also of having a reasonable representation of participants from across communities in the Riyadh region. We summarized categorical variables using frequencies and percentages, and for continuous variables, we used means and standard deviations (SDs) or medians and
IQRs. To compare proportions of participants in different groups, we used the Chi-square or Fisher's exact test for categorical variables, the student's t-test or MannWhitney $U$ test for continuous variables between two groups, and analysis of variance or the Kruskal-Wallis test for continuous variables among more than two groups. Age was categorized into three groups: 35-49 years, $50-59$ years, and $60-70$ years. Education was categorized as high (i.e., trade school, college, or university), medium (i.e., secondary school or high school), low (i.e., primary education or no education), or unknown. We also calculated the incidence rate of events taking into account follow-up duration and time to the corresponding events in 100-person years. All statistical analyses were performed using SAS version 9.2 (SAS Institute, Inc., Cary, NC, USA). A $P$ value of less than 0.05 was considered statistically significant.

\section{Human participant protection}

The King Saud University Ethics Committee granted ethics approval for the study. Participation in the study was voluntary, and all eligible participants who provided written informed consent were enrolled.

\section{Results \\ Overall cohort}

The PURE-Saudi study enrolled 2047 participants, with a mean age of $46.5 \pm 9.12$ years (Table 1 ). There were 1165 men (56.9\%) and 882 women (43.1\%). Around one third of the total cohort had a low educational level.

\section{CVD risk factors}

The mean BMI of the participants was 30.6, with the majority either overweight (35.3\%) or obese (49.6\%). Among patients with obesity, $30 \%$ had a BMI of 30-35, and $19.5 \%$ had a BMI $>35$. The prevalence of abdominal obesity, defined as a waist circumference $>102 \mathrm{~cm}$ (men) or $>88 \mathrm{~cm}$ (women), was $49 \%$. This prevalence increased to $74.3 \%$ when the waist circumference cutoff was $>90$ $\mathrm{cm}$ (men) or $>85 \mathrm{~cm}$ (women).

The prevalence of hypertension was $30.3 \%$, of whom only $61.1 \%$ were aware of it, $58.9 \%$ were treated, and $30.7 \%$ had achieved blood pressure control. The prevalence of diabetes was $25.1 \%$, and of these participants, $2.7 \%$ were on insulin therapy, $60.7 \%$ received oral hypoglycemic agents (OHAs), 6.6\% received both (insulin and OHAs), and 30\% received no treatment. About one third (32.1\%) had a high total cholesterol level, and $1 \%$ had a history of stroke, $0.6 \%$ a history of heart failure, and $2.5 \%$ a history of coronary heart disease. The median INTERHEART risk score for the total cohort was 11 . 
Table 1 Characteristics and the prevalence of cardiovascular disease risk factors in the PURE-Saudi study

\begin{tabular}{|c|c|c|c|c|}
\hline Characteristics & Overall & Men & Women & $p^{1}$ \\
\hline $\mathrm{N}(\%)$ & 2047 & $1165(56.9)$ & $882(43.1)$ & \\
\hline \multicolumn{5}{|l|}{ Demographics } \\
\hline Age $(y)$, mean $\pm S D$ & $46.5 \pm 9.1$ & $47.5 \pm 9.4$ & $45.1 \pm 8.5$ & $<0.001$ \\
\hline Low educational level, n (\%) & $646(31.6)$ & $235(20.2)$ & $411(46.6)$ & $<0.001$ \\
\hline \multicolumn{5}{|l|}{ Behavioral risk factors } \\
\hline \multicolumn{5}{|l|}{ Smoking status, n (\%) } \\
\hline Current smoker & $249(12.2)$ & $245(21)$ & $4(0.4)$ & $<0.001$ \\
\hline Former smoker & $217(10.6)$ & $209(17.9)$ & $8(0.9)$ & $<0.001$ \\
\hline Unhealthful diet, n (\%) & $702(34.4)$ & $397(56.5)$ & $305(43.4)$ & 0.827 \\
\hline Low physical activity, n (\%) & $1415(69.4)$ & $805(69.3)$ & $610(69.5)$ & 0.946 \\
\hline Current alcohol use, n (\%) & $24(1.2)$ & $24(2.1)$ & $0(0.0)$ & $<0.001$ \\
\hline \multicolumn{5}{|l|}{ Hypertension } \\
\hline Hypertension, n (\%) & $620(30.3)$ & $382(32.8)$ & $238(27)$ & 0.005 \\
\hline Awareness among patients with known hypertension, $\mathrm{n}(\%)$ & $379(61.1)$ & $233(61)$ & $146(61.3)$ & 0.931 \\
\hline Treated hypertension among patients with known hypertension, n (\%) & $365(58.9)$ & $220(57.6)$ & $145(60.9)$ & 0.412 \\
\hline Controlled hypertension among those with known hypertension, n (\%) & $190(30.6)$ & $108(28.3)$ & $82(34.4)$ & 0.104 \\
\hline Treated hypertension and SBP $\geq 140 \mathrm{mmHg}$ and/or DBP $\geq 90 \mathrm{mmHg}, \mathrm{n}(\%)$ & $175(47.9)$ & $112(50.9)$ & $63(43.4)$ & 0.163 \\
\hline Treated hypertension and SBP > $120 \mathrm{mmHg}$ and/or DBP > $80 \mathrm{mmHg}, \mathrm{n}(\%)$ & $318(87.1)$ & $198(90)$ & $120(82.8)$ & 0.043 \\
\hline Treated hypertension and SBP > $130 \mathrm{mmHg}$ and/or DBP > 80 mmHg, $\mathrm{n}(\%)$ & $272(76.2)$ & $173(79.4)$ & $99(71.2)$ & 0.078 \\
\hline \multicolumn{5}{|l|}{ Diabetes } \\
\hline Diabetes, n (\%) & $516(25.2)$ & $328(28.1)$ & $188(21.3)$ & $<0.001$ \\
\hline Among patients with diabetes & & & & 0.093 \\
\hline On insulin alone & $14(2.7)$ & $5(1.5)$ & $9(4.8)$ & \\
\hline On OHA alone & $313(60.7)$ & $200(61)$ & $113(60.1)$ & \\
\hline On both & $34(6.6)$ & $19(5.8)$ & $15(8)$ & \\
\hline Not on prescription drug & $155(30)$ & $104(31.7)$ & $51(27.1)$ & \\
\hline \multicolumn{5}{|l|}{ Dyslipidemia } \\
\hline $\begin{array}{l}\text { Total cholesterol }>5.2 \mathrm{mmol} / \mathrm{l} \text { and low-density lipoprotein } \\
\text { cholesterol }>3.5 \mathrm{mmol} / \mathrm{l}, \mathrm{n}(\%)\end{array}$ & $569(32.1)$ & $234(31.2)$ & $335(32.7)$ & 0.508 \\
\hline \multicolumn{5}{|l|}{ Obesity } \\
\hline BMI, mean & $30.6 \pm 5.9$ & $29.7 \pm 5.4$ & $31.94 \pm 6.3$ & $<0.001$ \\
\hline BMI, n (\%) & & & & $<0.001$ \\
\hline$<25$ & $310(15.1)$ & $205(17.6)$ & $105(11.9)$ & \\
\hline $25-30$ & $722(35.3)$ & $462(39.7)$ & $260(29.5)$ & \\
\hline $31-35$ & $613(30)$ & $463(39.8)$ & $286(32.4)$ & \\
\hline$>35$ & $399(19.5)$ & $169(14.5)$ & $230(26.1)$ & \\
\hline \multicolumn{5}{|l|}{ Abdominal obesity, n (\%) } \\
\hline Waist circumference $>102 \mathrm{~cm}$ (men) or $>88 \mathrm{~cm}$ (women) & $1005(49)$ & $381(32.7)$ & $624(70.7)$ & $<0.001$ \\
\hline Waist circumference $>90 \mathrm{~cm}$ (men) or $>85 \mathrm{~cm}$ (women) & $1521(74.3)$ & $835(71.7)$ & $686(77.8)$ & 0.002 \\
\hline \multicolumn{5}{|l|}{ Psychosocial } \\
\hline Self-report of feeling sad or "blue," n (\%) & $315(15.4)$ & $115(9.9)$ & $200(22.7)$ & $<0.001$ \\
\hline \multicolumn{5}{|l|}{ General feeling of stress, n (\%) } \\
\hline Several periods of stress & $339(16.9)$ & $143(12.4)$ & $196(23.1)$ & $<0.001$ \\
\hline Permanent stress & $136(6.8)$ & $52(4.5)$ & $84(9.9)$ & $<0.001$ \\
\hline
\end{tabular}


Table 1 Characteristics and the prevalence of cardiovascular disease risk factors in the PURE-Saudi study (Continued)

\begin{tabular}{|c|c|c|c|c|}
\hline Characteristics & Overall & Men & Women & $p^{1}$ \\
\hline \multicolumn{5}{|l|}{ Medical history } \\
\hline $\begin{array}{l}\text { History of ischemic heart disease (angina, myocardial infarction, } \\
\text { or any coronary revascularization), n (\%) }\end{array}$ & $51(2.5)$ & $37(3.2)$ & $14(1.6)$ & 0.022 \\
\hline History of stroke, n (\%) & $20(1)$ & $12(1)$ & $8(0.9)$ & 0.779 \\
\hline History of heart failure, n (\%) & $13(0.6)$ & $5(0.4)$ & $8(0.9)$ & 0.178 \\
\hline INTERHEART Risk Score, median (25th-75th, IQR) & $11(8,16)$ & $13(9,18)$ & $10(6,14)$ & $<0.001$ \\
\hline
\end{tabular}

$B M I$ body mass index, $D B P$ diastolic blood pressure, $I Q R$ interquartile range, $O H A$ oral hypoglycemic agent, $S B P$ systolic blood pressure

${ }^{1} P$ values refer to the results of either Chi-square tests (for categorical variables) or t-tests (for continuous variables comparing the mean between categories

\section{Health behaviors and psychosocial factors}

Approximately $34.4 \%$ of the total cohort reported eating an unhealthy diet, $69.4 \%$ reported low physical activity, $12.2 \%$ were current smokers, and $10.6 \%$ were former smokers. Moreover, the prevalence of self-reported sadness or feeling blue was $15.4 \%$, whereas $16.9 \%$ reported a history of feeling stress during several periods, and $6.8 \%$ had a permanent feeling of stress.

\section{Men compared with women}

Compared with women, men had a significantly higher proportion of current smoking $(21 \%$ vs $0.45 \%, P<0.001)$ or former smoking $(17.9 \%$ vs $0.91 \%, P<0.001)$, diabetes (28.2\% vs $21.3 \%, P<0.001)$, obesity with BMI $30-35$ (39.9\% vs $32.4 \%, P<0.001$ ), and history of ischemic heart disease $(3.2 \%$ vs $1.6 \%, P=0.02)$, and a higher median INTERHEART risk score $(13 \%$ vs $10 \%, P<0.001)$. Women had higher prevalence of obesity with BMI $>35$ (26.1\% vs $14.5 \%, P<0.001)$, central obesity $(70.7 \%$ vs $32.7 \%, P<0.001)$, self-reported sadness $(22.7 \%$, vs $9.9 \%$, $P<0.001)$, several periods of stress $(23.1 \%$ vs $12.4 \%, P<$ $0.001)$, a permanent feeling of stress $(9.9 \%$ vs $4.5 \%, P<$
0.001), and low level of education (46.6\% vs $20.2 \%, P<$ 0.001) (Table 1 and Fig. 1).

Regarding blood pressure, for women compared with men, awareness $(61.3 \%$ vs $60.9 \%, P=0.93)$, treatment (60.9\% vs $57.6 \%, P=0.41)$, and control $(34.5 \%$ vs $28.3 \%$, $P=0.10)$ were similar. Men were more likely, however, to have lower high-density lipoprotein cholesterol levels compared with women (Additional Table 1).

\section{Young vs middle vs old age}

Compared to the younger and middle age groups (35-49 years and 50-59 years), older participants (60-70 years) had a higher prevalence of low physical activity $(66.8 \%$ younger vs $73.9 \%$ middle vs $75.2 \%$ older, $P=0.002$ ), hypertension $(18.2 \%$ vs $48.4 \%$ vs $65 \%, P<0.001)$, diabetes (12.9\% vs $45 \%$ vs $57.5 \%, P<0.001$ ), low education level ( $21.7 \%$ vs $45 \%$ vs $62.8 \%, P<0.001)$, stroke $(0.4 \%$ vs $1.1 \%$ vs $4 \%, P<0.001)$, history of heart failure $(0.1 \%$ vs $1.5 \%$ vs $1.8 \%, P<0.001)$, and history of ischemic heart disease (1.1\% vs $4.1 \%$ vs $7.5 \%, P<0.001$ ) (Table 2 and Fig. 2). Awareness and treatment of blood pressure were higher among older participants compared with middle-aged and

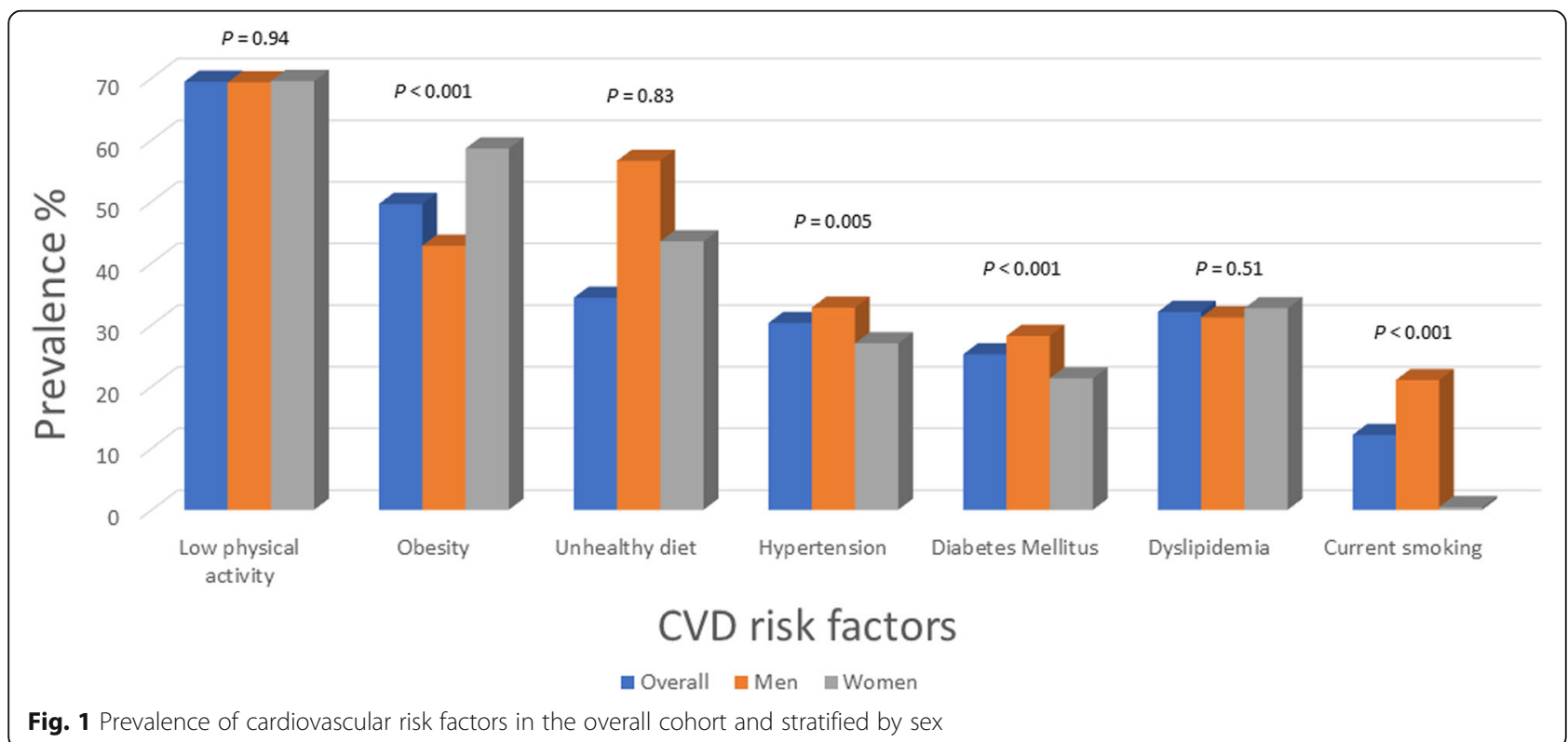


younger individuals (awareness: $45.5 \%$ for younger vs $70 \%$ middle-aged vs $73.5 \%$ older; $40.7 \%$ vs $69.2 \%$ vs $73.5 \%$ for treatment; $P<0.0001$ for all).

A greater proportion of middle-aged participants (39.2\%) had more controlled blood pressure compared to younger (19.9\%) and older $(35.4 \%)$ individuals $(P<0.0001)$. However, the younger age group more often reported consumption of an unhealthy diet (38.9\% vs $25.2 \%$ middle-aged vs $26.5 \%$ older respondents, $P<0.001$ ), general feeling of permanent stress $(9.1 \%$ vs $2.4 \%$ vs $1.9 \%, P<0.001)$, and being sad $(18.6 \%$ vs $10 \%$ vs $7.1 \%, P<0.001)$. The prevalence of obesity with BMI $30-35$ and BMI $>35$ was 34.1 and $21.8 \%$ in the middle-aged group compared to 28.7 and $19.4 \%$ in the younger group and 28.8 and $15.5 \%$ in older age groups $(P<0.001)$ respectively. Moreover, the median level of glucose and triglycerides was significantly increased in the older age group (Additional Table 2).

\section{Urban vs rural}

Of the cohort, $75.48 \%$ lived in urban areas. Compared to those in urban areas, a greater proportion of those living in rural areas reported diabetes (31.1\% rural vs $23.3 \%$ urban, $P<0.001)$, obesity (56.6\% vs $47.3 \%, P<0.001$ ), hypertension ( $35.5 \%$ vs $28.6 \%, P=0.004)$, and low education level $(46.4 \%$ vs $26.7 \%, P<0.001)$. In addition, the median BMI was higher among rural compared to urban participants $(30.8 \%$ vs $29.7 \%, P<0.001)$. On the other hand, urban participants were more likely to consume unhealthy diet ( $36 \%$ vs $29.4 \%, P=0.007$ ), self-report being sad $(17.6 \%$ vs $8.6 \%, P<0.001)$, have several periods of stress $(19.7 \%$ vs $8.7 \%, P<0.001)$, and have a permanent feeling of stress $(8.03 \%$ vs $3.02 \%, P<0.001)$ (Table 3 and Fig. 3).

The awareness, treatment, and control of blood pressure were similar between the urban and rural communities (awareness: $62.2 \%$ urban vs $58.4 \%$ rural, $P=0.38$; treatment: $60.1 \%$ vs $55.6 \%, P=0.29$; control: $32.6 \%$ vs $25.8 \%, P=0.10)$. Furthermore, urban participants had a higher median glucose level and higher proportion with a glucose level of $6-7 \mathrm{mmol} / \mathrm{l}$ in participants without diabetes (Additional Table 3).

\section{Follow-up}

Of 2047 participants, 1996 responded to follow-up after baseline, for a response rate of $97.5 \%$. Current mean (SD) and median (IQR) duration of follow-up is 4.3 (1.4) and 3.4 (3.2-6.1) years, respectively. We have attempted to contact participants at least three times. During the current follow-up, 6 patients had been diagnosed with cancer (0.07 per 100 person years of follow-up), and there were 22 deaths $(0.26$ per 100 person years of follow-up). The overall rates of major cardiovascular events showed a pattern similar to that for mortality: 24 had a myocardial infarction $(0.29$ per 100 person years of follow-up), 6 had a stroke (0.07 per 100 person years of follow-up), 4 had heart failure ( 0.05 per 100 person years of follow-up), and 34 had at least one major cardiovascular event (0.41 per 100 person years of followup).

\section{Discussion \\ Main findings}

The PURE-Saudi study allows for assessment of the prevalence of unhealthy lifestyle behaviors and CVD risk factors, stratified by age, sex, and place of residence. Because the work relies on internationally standardized and validated surveys of the global PURE study, valid interpretation and direct comparison of the results are possible in the context of other enrolled countries with variable economic scales and healthcare systems. Our study yielded two major findings. First, CVD risk factor prevalence is high in the Saudi population, including two thirds with low physical activity, half with obesity, one third who consume an unhealthy diet, one third with dyslipidemia, one third with hypertension, and one quarter with diabetes. Second, the relative proportion of the individual CVD risk factors varies with age, sex, and urban vs rural residence.

\section{CVD risk factor prevalence in comparison with previous findings}

The PURE-Saudi study confirms that the prevalence of unhealthy life styles and coronary artery disease risk factors remains high in the Saudi population. These findings are in keeping with a decade of several previous population cross-sectional surveys (Additional Table 4) showing a high prevalence of hypercholesterolemia, obesity, hypertension, diabetes, smoking, physical inactivity, and diabetes in Saudi Arabia. The Coronary Artery Disease in the Saudis Study was a national epidemiological health survey conducted between 1995 to 2000 that included 17,395 Saudis ages 30-70 years through a multistage stratified cluster sampling technique. The overall prevalences were 54\% for hypercholesterolemia, $35.6 \%$ for obesity, $26.1 \%$ for hypertension, $23.7 \%$ for diabetes, and $12.8 \%$ for smoking [11-13, 2325]. Another national cross-sectional survey by the Saudi Ministry of Health involved 4758 participants ages 15 to 64 years and aimed to estimate the prevalence of some risk factors for non-communicable diseases by using the World Health Organization's STEPwise approach for non-communicable disease surveillance. These results indicated prevalences of $67.6 \%$ for physical inactivity, $36.2 \%$ for obesity, $19.1 \%$ for hypercholesterolemia, $11.6 \%$ for hypertension, $15.3 \%$ for diabetes, and $10.9 \%$ for current daily smoking [14]. The Saudi Health Information Survey, also conducted by the Ministry of Health, enrolled 10,735 Saudis ages 15 years or older in 2013. 
Table 2 Prevalence of cardiovascular disease risk factors stratified by age groups in the PURE-Saudi study

\begin{tabular}{|c|c|c|c|c|}
\hline Characteristics & $35-49 y$ & $50-59 y$ & $60-70 y$ & $P^{1}$ \\
\hline $\mathrm{N}(\%)$ & $1352(66)$ & $469(22.9)$ & $226(11)$ & \\
\hline \multicolumn{5}{|l|}{ Demographics } \\
\hline Low education level, n (\%) & $293(21.7)$ & $211(45)$ & $142(62.8)$ & $<0.001$ \\
\hline \multicolumn{5}{|l|}{ Behavioral risk factors } \\
\hline \multicolumn{5}{|l|}{ Smoking status, n (\%) } \\
\hline Current smoker & $181(13.4)$ & $48(10.2)$ & $20(8.8)$ & 0.054 \\
\hline Former smoker & $124(9.2)$ & $60(12.8)$ & $33(14.6)$ & 0.011 \\
\hline Unhealthful diet, n (\%) & $524(38.9)$ & $118(25.2)$ & $60(26.5)$ & $<0.001$ \\
\hline Low physical activity, n (\%) & $899(66.8)$ & $346(73.9)$ & $170(75.2)$ & 0.002 \\
\hline Current alcohol use, n (\%) & $14(1)$ & $7(1.5)$ & $3(1.3)$ & 0.632 \\
\hline \multicolumn{5}{|l|}{ Hypertension } \\
\hline Hypertension, n (\%) & $246(18.2)$ & $227(48.4)$ & $147(65)$ & $<0.001$ \\
\hline Awareness among patients with known hypertension, $\mathrm{n}(\%)$ & $112(45.5)$ & $159(70)$ & $108(73.5)$ & $<0.001$ \\
\hline Treated hypertension among patients with known hypertension, n (\%) & $100(40.6)$ & $157(69.2)$ & $108(73.5)$ & $<0.001$ \\
\hline Controlled hypertension among those with known hypertension, n (\%) & $49(19.9)$ & $89(39.2)$ & $52(35.4)$ & $<0.001$ \\
\hline Treated hypertension and SBP $\geq 140 \mathrm{mmHg}$ and/or DBP $\geq 90 \mathrm{mmHg}, \mathrm{n}(\%)$ & $51(51)$ & $68(43.3)$ & $56(51.8)$ & 0.304 \\
\hline Treated hypertension and SBP > $120 \mathrm{mmHg}$ and/or DBP > 80 mmHg, $\mathrm{n}(\%)$ & $86(86)$ & $135(86)$ & $97(89.8)$ & 0.609 \\
\hline Treated hypertension and SBP > $130 \mathrm{mmHg}$ and/or DBP > $80 \mathrm{mmHg}, \mathrm{n}(\%)$ & $80(80.8)$ & $115(73.7)$ & $77(75.5)$ & 0.423 \\
\hline \multicolumn{5}{|l|}{ Diabetes } \\
\hline Diabetes, n (\%) & $175(12.9)$ & $211(45)$ & $130(57.5)$ & $<0.001$ \\
\hline Among patients with diabetes & & & & 0.831 \\
\hline On insulin alone & $5(2.9)$ & $6(2.8)$ & $3(2.3)$ & \\
\hline On OHA alone & $105(60)$ & $130(61.6)$ & $78(60)$ & \\
\hline On both & $12(6.9)$ & $10(4.7)$ & $12(9.2)$ & \\
\hline Not on prescription drug & $53(30.3)$ & $65(30.8)$ & $37(28.5)$ & \\
\hline \multicolumn{5}{|l|}{ Dyslipidemia } \\
\hline Total cholesterol > $5.2 \mathrm{mmol} / \mathrm{l}$ and low-density lipoprotein cholesterol > $3.5 \mathrm{mmol} / \mathrm{l}, \mathrm{n}(\%)$ & $380(32.4)$ & $124(29.9)$ & $65(34.2)$ & 0.514 \\
\hline \multicolumn{5}{|l|}{ Obesity } \\
\hline BMI, mean & $30.6 \pm 6$ & $31.4 \pm 5.5$ & $29.5 \pm 5.7$ & 0.003 \\
\hline BMI, n (\%) & & & & $<0.001$ \\
\hline$<25.0$ & $211(15.6)$ & $46(9.8)$ & $53(23.4)$ & \\
\hline $25.0-30.0$ & $488(36.1)$ & $161(34.3)$ & $73(32.3)$ & \\
\hline $30.1-35.0$ & $388(28.7)$ & $160(34.1)$ & $65(28.8)$ & \\
\hline$>35.0$ & $262(19.4)$ & $102(21.7)$ & $35(15.5)$ & \\
\hline \multicolumn{5}{|l|}{ Abdominal obesity, n (\%) } \\
\hline Waist circumference $>102 \mathrm{~cm}$ (men) or $>88 \mathrm{~cm}$ (women) & $628(46.4)$ & $262(55.9)$ & $115(50.9)$ & 0.002 \\
\hline Waist circumference $>90 \mathrm{~cm}$ (men) or $>85 \mathrm{~cm}$ (women) & $960(71)$ & $389(82.9)$ & $172(76.1)$ & $<0.001$ \\
\hline \multicolumn{5}{|l|}{ Psychosocial } \\
\hline Self-report of being sad or "blue," n (\%) & $252(18.6)$ & $47(10)$ & $16(7.1)$ & $<0.001$ \\
\hline \multicolumn{5}{|l|}{ General feeling of stress, n (\%) } \\
\hline Several periods of stress & $249(18.6)$ & $74(16.3)$ & $16(7.5)$ & $<0.001$ \\
\hline Permanent stress & $121(9.1)$ & $11(2.4)$ & $4(1.9)$ & $<0.001$ \\
\hline
\end{tabular}


Table 2 Prevalence of cardiovascular disease risk factors stratified by age groups in the PURE-Saudi study (Continued)

\begin{tabular}{|c|c|c|c|c|}
\hline Characteristics & $35-49$ y & $50-59 y$ & $60-70$ y & $P^{1}$ \\
\hline \multicolumn{5}{|l|}{ Medical history } \\
\hline History of ischemic heart disease (angina or myocardial infarction), n (\%) & $15(1.1)$ & $19(4.0)$ & $17(7.5)$ & $<0.001$ \\
\hline History of stroke, n (\%) & $6(0.4)$ & $5(1.1)$ & $9(4)$ & $<0.001$ \\
\hline History of heart failure, n (\%) & $2(0.1)$ & $7(1.5)$ & $4(1.8)$ & $<0.001$ \\
\hline INTERHEART Risk Score, median (25th-75th, IQR) & $10(7,14)$ & $14(10,19)$ & $16(12,21)$ & $<0.001$ \\
\hline
\end{tabular}

$B M I$ body mass index, $D B P$ diastolic blood pressure, $I Q R$ interquartile range, $O H A$ oral hypoglycemic agent, $S B P$ systolic blood pressure

${ }^{1} P$ values refer to the results of either chi-square tests (for categorical variables) or analysis of variance (for continuous variables comparing the mean across categories)

The prevalences were $39.8 \%$ for low physical activity, $28.7 \%$ for obesity, $61.6 \%$ for daily consumption of $<2$ servings of fruits and vegetables, $15.2 \%$ for hypertension, $13.4 \%$ for diabetes, $8.5 \%$ for hypercholesterolemia, and $12.1 \%$ for smoking $[9,10,28,29,41]$. As a result of such a high prevalence of CVD risk factors, patients in Saudi Arabia present almost a decade younger than average for developed countries with acute coronary syndromes and acute heart failure and thus are at high risk for cardiovascular complications and mortality [42-44].

\section{Diabetes and hypertension}

Compared with the general population, patients with diabetes are 2 to 4 times more likely to develop CVD [45]. According to the International Diabetes Federation Diabetes Atlas (8th edition), Saudi Arabia is among the top 10 countries in diabetes prevalence [46], which is estimated to increase by $110 \%$ in the Middle East and North Africa by 2045. The prevalence in PURE Saudi was among the highest levels reported in the global PURE data. Overall, diabetes prevalence was $11 \%$, varying among country income groups, with the lowest value $(6.6 \%)$ in high-income countries and the highest (12.3\%) in low-income countries [47]. Moreover, analysis of the global PURE data showed that hypertension prevalence was $40.8 \%$ and that only a third of patients had reached their blood pressure targets [48]. A report of prevalence, awareness, treatment, and control of hypertension from baseline PURE data from four Middle East countries [Iran, Occupied Palestinian Territory (OPT), Saudi Arabia, and the United Arab Emirates (UAE)] showed that one third had hypertension, about half of whom were aware and treated, and only one fifth were controlled [49]. The prevalence of hypertension was highest in the UAE (52\%) and lowest in Iran (28\%), whereas awareness, treatment, and control of hypertension were higher in the OPT and Saudi Arabia compared with the UAE and Iran [49].

Other national studies have found suboptimal hypertension control in the Saudi population [7, 24]. Affordability of medications is one of the main reasons for the low rate of hypertension control globally [50], but in Saudi Arabia, healthcare and medications are free,

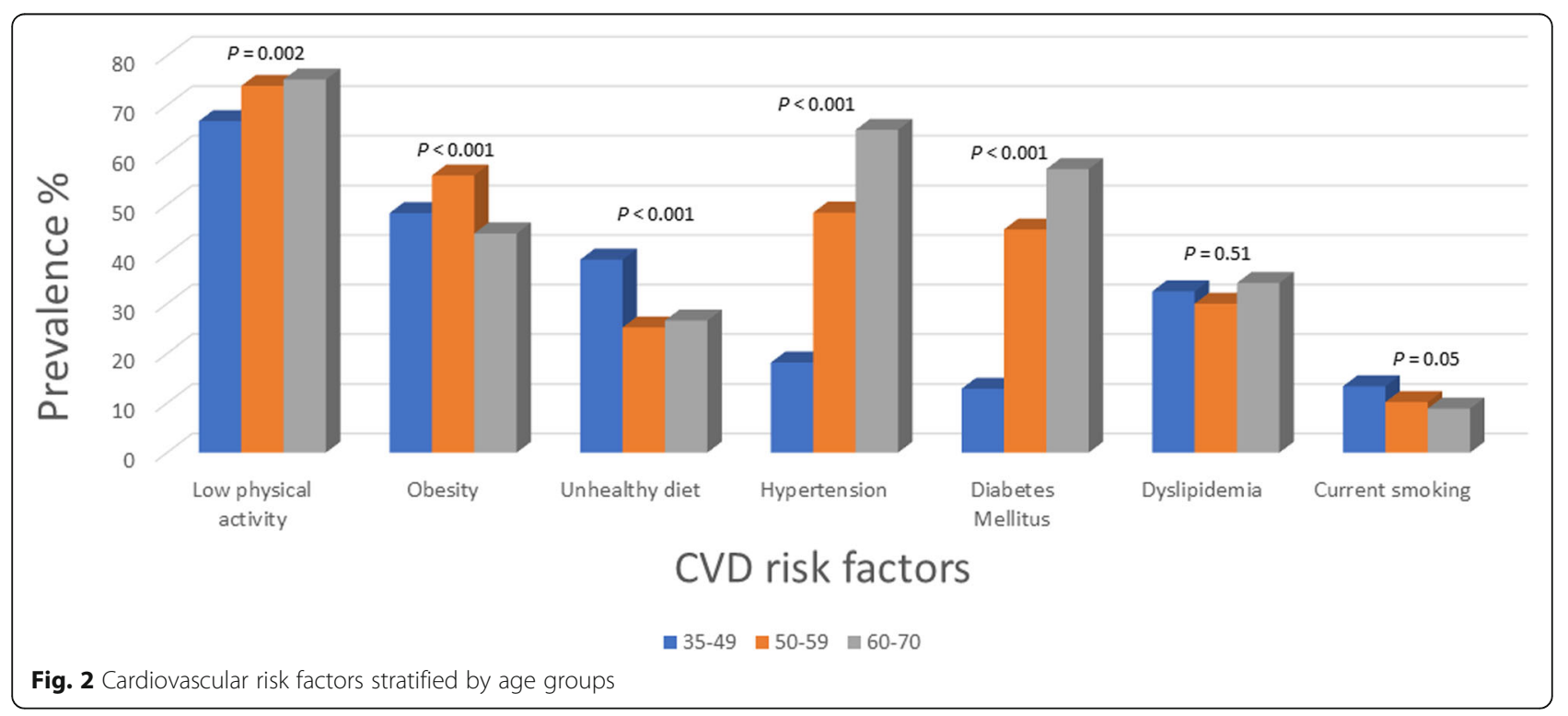


Table 3 Prevalence of cardiovascular disease risk factors stratified by place of residence in the PURE-Saudi study

\begin{tabular}{|c|c|c|c|}
\hline Characteristics & Urban & Rural & $P^{1}$ \\
\hline $\mathrm{N}(\%)$ & $1545(75.5)$ & $502(24.5)$ & \\
\hline \multicolumn{4}{|l|}{ Demographics } \\
\hline Age $(y)$, mean $\pm S D$ & $46.3 \pm 8.9$ & $47.1 \pm 9.8$ & 0.124 \\
\hline Low education level, n (\%) & $413(26.7)$ & $233(46.4)$ & $<0.001$ \\
\hline \multicolumn{4}{|l|}{ Behavioral risk factors } \\
\hline \multicolumn{4}{|l|}{ Smoking status, n (\%) } \\
\hline Current smoker & $198(12.8)$ & $51(10.2)$ & 0.114 \\
\hline Former smoker & $175(11.3)$ & $42(8.4)$ & 0.061 \\
\hline Unhealthful diet, n (\%) & $556(36)$ & $146(29.4)$ & 0.007 \\
\hline Low physical activity, n (\%) & $1061(68.7)$ & $354(71.5)$ & 0.240 \\
\hline Current alcohol use, n (\%) & $18(1.2)$ & $6(1.2)$ & 0.956 \\
\hline \multicolumn{4}{|l|}{ Hypertension } \\
\hline Hypertension, n (\%) & $442(28.6)$ & $178(35.5)$ & 0.004 \\
\hline Awareness among patients with known hypertension, $\mathrm{n}(\%)$ & $275(62.2)$ & $104(58.4)$ & 0.381 \\
\hline Treated hypertension among patients with known hypertension, n (\%) & $266(60.2)$ & $99(55.6)$ & 0.296 \\
\hline Controlled hypertension among those with known hypertension, n (\%) & $144(32.6)$ & $46(25.8)$ & 0.100 \\
\hline Treated hypertension and SBP $\geq 140 \mathrm{mmHg}$ and/or DBP $\geq 90 \mathrm{mmHg}, \mathrm{n}(\%)$ & $122(45.9)$ & $53(53.5)$ & 0.192 \\
\hline Treated hypertension and SBP > $120 \mathrm{mmHg}$ and/or DBP > $80 \mathrm{mmHg}, \mathrm{n}(\%)$ & $227(85.3)$ & $91(91.9)$ & 0.095 \\
\hline Treated hypertension and SBP > $130 \mathrm{mmHg}$ and/or DBP > $80 \mathrm{mmHg}, \mathrm{n}(\%)$ & $191(73.5)$ & $81(83.5)$ & 0.047 \\
\hline \multicolumn{4}{|l|}{ Diabetes } \\
\hline Diabetes, n (\%) & $360(23.3)$ & $156(31.1)$ & $<0.001$ \\
\hline Among patients with diabetes & & & $<0.001$ \\
\hline On insulin alone & $11(3.1)$ & $3(1.9)$ & \\
\hline On OHA alone & $249(69.2)$ & $64(41.0)$ & \\
\hline On both & $31(8.6)$ & $3(1.9)$ & \\
\hline Not on prescription drug & $69(19.2)$ & $86(55.1)$ & \\
\hline \multicolumn{4}{|l|}{ Dyslipidemia } \\
\hline Total cholesterol > $5.2 \mathrm{mmol} / \mathrm{l}$ and low-density lipoprotein cholesterol > $3.5 \mathrm{mmol} / \mathrm{l}, \mathrm{n}(\%)$ & $439(31.5)$ & $130(34.1)$ & 0.330 \\
\hline \multicolumn{4}{|l|}{ Obesity } \\
\hline BMl, mean & $30.4 \pm 5.8$ & $31.4 \pm 6.2$ & 0.037 \\
\hline BMI, n (\%) & & & $<0.001$ \\
\hline$<25.0$ & $245(15.9)$ & $65(12.9)$ & \\
\hline $25.0-30.0$ & $569(36.8)$ & $153(30.5)$ & \\
\hline $30.1-35.0$ & $454(29.4)$ & $159(31.7)$ & \\
\hline$>35.0$ & $275(17.8)$ & $124(24.7)$ & \\
\hline \multicolumn{4}{|l|}{ Abdominal obesity, n (\%) } \\
\hline Waist circumference $>102 \mathrm{~cm}$ (men) or $>88 \mathrm{~cm}$ (women) & $754(48.8)$ & $251(50)$ & 0.641 \\
\hline Waist circumference $>90 \mathrm{~cm}$ (men) or $>85 \mathrm{~cm}$ (women) & $1156(74.8)$ & $365(72.7)$ & 0.347 \\
\hline \multicolumn{4}{|l|}{ Psychosocial } \\
\hline Self-report of being sad or "blue," n (\%) & $272(17.6)$ & $43(8.6)$ & $<0.001$ \\
\hline \multicolumn{4}{|l|}{ General feeling of stress, n (\%) } \\
\hline Several periods of stress & $296(19.6)$ & $43(8.7)$ & $<0.001$ \\
\hline Permanent stress & $121(8)$ & $15(3)$ & $<0.001$ \\
\hline
\end{tabular}


Table 3 Prevalence of cardiovascular disease risk factors stratified by place of residence in the PURE-Saudi study (Continued)

\begin{tabular}{|c|c|c|c|}
\hline Characteristics & Urban & Rural & $p^{1}$ \\
\hline \multicolumn{4}{|l|}{ Medical history } \\
\hline History of ischemic heart disease (angina or myocardial infarction), n (\%) & $36(2.3)$ & $15(3)$ & 0.411 \\
\hline History of stroke, n (\%) & $12(0.8)$ & $8(1.6)$ & 0.118 \\
\hline History of heart failure, n (\%) & $8(0.5)$ & $5(1)$ & 0.327 \\
\hline INTERHEART Risk Score, median (25th-75th, IQR) & $11(8,16)$ & $12(7,17)$ & 0.833 \\
\hline
\end{tabular}

$B M I$ body mass index, $D B P$ diastolic blood pressure, $I Q R$ interquartile range, $O H A$ oral hypoglycemic agent, $S B P$ systolic blood pressure

${ }^{1} P$ values refer to the results of either Chi-square tests (for categorical variables) or t-tests (for continuous variables comparing the mean between categories

making them largely accessible to the population. Patients, physicians, and healthcare systems face several barriers in pursuing control of hypertension, indicating the need for multifaceted interventions [51, 52]. Forgetting to take medical therapies and medication side effects are important barriers to adherence [52]. Analysis of data from a large household survey of 10,735 participants to identify barriers to healthcare in Saudi Arabia found that neither distance to nor type of healthcare clinic were barriers to management of chronic diseases and highlighted the importance of an individual's healthcare-seeking practices rather than system-related factors as potential barriers. It is possible that some in the Saudi population have specific healthcare-seeking practices that involve their seeking healthcare primarily when they feel unwell, contradicting the concept of an old Arab proverb, "Prevention is better than treatment" [53]. A lack knowledge and awareness of hypertension guidelines among primary care physicians also has been reported, with one survey finding that one fourth of 322 primary care physicians had deficient knowledge about the correct definition of hypertension [54]. Regarding the healthcare system barriers, inappropriate coordination among medical sectors has been reported, with about one third of Saudi patients with hypertension not having a record of the diagnosis on file at the primary healthcare centers and receiving medical care in different healthcare sectors that led to missing their regular appointments [51].

\section{Obesity}

The overall prevalence of obesity in this study was approximately $49.6 \%$, which was higher than the most recent national surveys conducted in Saudi Arabia, $[9,55]$ indicating the lack of effect of obesity prevention programs in the kingdom. In addition, a number of risk factors have been correlated with the increased prevalence of obesity in the country, including sedentary lifestyle and increasing trend in energy intake [56].

Our findings support those of a secondary analysis of published data that estimated trends and projections in the age- and sex-specific prevalence of adult obesity in Saudi Arabia over the 30-year period of 1992-2022 [55]. The prevalence of obesity was projected to increase markedly (by more than 200\%) among men and women aged 25-64 years, with women having much higher

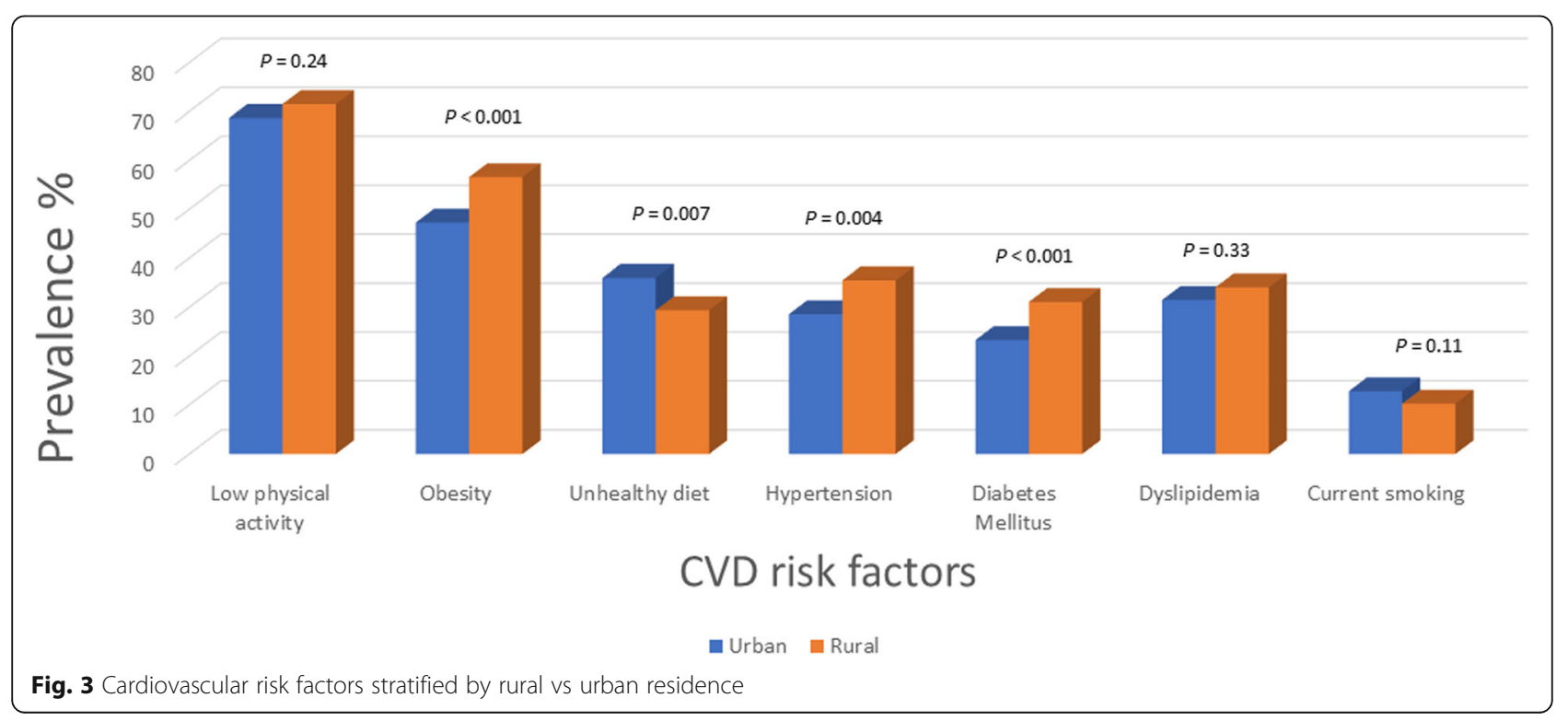


projected prevalences than men [55]. One of the main findings of PURE Saudi is that women are more obese compared to men. A possible explanation of this higher obesity prevalence among women in this cohort may be sociocultural factors and governmental bylaws. These factors include the requirement until recently that women have a driver for transportation purposes, along with barriers to engaging in physical activities in public places. Increasing women's access to exercise facilities and providing safe walking areas are likely to help to reduce the obesity prevalence. Recently, gymnasiums for women in Saudi Arabia have become more accessible, and women are now allowed to drive by themselves, which could potentially improve access to a healthier lifestyle. On the other hand, the lower rate of diabetes in women compared with men in our study may be attributed to the well-recognized greater willingness of women than men to seek medical advice [57]. In addition, women are also more willing than men to adhere to daily management of diabetes, such as restricted diet, blood glucose monitoring, and prescribed medication [58].

\section{Urban vs rural}

Another important issue to highlight is the common belief that the risk of developing CVD is higher in individuals living in urban vs rural areas [59]. Findings from the global PURE cohort from high-income countries reported a similar INTERHEART risk score between populations in rural and urban areas [35]. However, the PURE Saudi study showed that the rural population had higher prevalence of CVD risk factors, particularly diabetes, hypertension, and obesity, compared to the urban population. Possible reasons might be related to what some researchers have called the "urbanization of rural life" [60], in which agriculture has become mechanized and cars are used for transport, road infrastructure has improved, and consumption of processed carbohydrates and commercially prepared and processed food has increased through the efforts of national and transnational companies, all of which would contribute to increased obesity [61-63]. In addition, the limited time and space for cooking healthy meals and possibly perceptions of greater weight as a sign of affluence could exacerbate these effects $[63,64]$. Furthermore, our findings might reflect less access to and/or low availability of a healthcare prevention and management facilities in rural areas. The reasons for these disparities may include inconsistent insurance policies, poor healthcare infrastructure and privatization, and accessibility to healthcare facilities that largely focus on the urban population, leaving the rural population disadvantaged [65]. The higher prevalence of diabetes in rural rather than urban areas provides support for the association between diabetes and lifestyle risk factors because lifestyle changes are less prominent in rural areas. In addition, the lower educational level among the rural population identified in this study could in part explain the differences in risk factor levels, similar to findings of the Vasterbotten Intervention Program study in Sweden [66]. For instance, a rural population with only a primary education level had a consistently higher prevalence of hypertension than an urban population with higher educational levels [66]. In the analysis of data from global PURE that were related to socioeconomic status and risk for CVD in 20 low-, middle-, and high-income countries, education, rather than wealth, was the socioeconomic indicator most consistently associated with outcomes, and major CVD events and all-cause mortality were more common among people with low levels of education in all types of country studied. However, variances in outcomes among educational levels were not explained by variances in risk factors, which decreased with increasing educational level in high-income countries, but increased with increasing educational level in low-income countries [67]. Furthermore, results from the MONICA (Monitoring trends and determinants in cardiovascular disease) study suggested that a lower education level among the rural population could enhance CVD risk, but causality is difficult to prove [68].

In the present study, a greater proportion of individuals living in urban areas reported having an unhealthy diet, sadness, and stress. A recent global systematic evaluation of dietary consumption patterns across 195 countries found that improvement in diet prevents one in every five deaths globally and that a suboptimal diet is responsible for more deaths than other risk factors, including smoking, highlighting the urgent need to improve diet [69]. Urbanization is also associated with factors that could potentially influence mental health and possibly the development of CVD, such as increased life stressors, overcrowding, a higher level of violence, and less social support [70]. However, in addition to stress caused by a transition from a rural to urban area, other cultural factors interplaying with urban dynamics might contribute to the development of psychologicalrelated problems. Therefore, understanding how cultural dynamics interact with adaptation to urban life may help in guiding appropriate management of mental disorders of people living in cities [71]. Awareness of the negative impact of urbanization on mental health is needed across Saudi society.

\section{Government recognition of the importance of the primary prevention of CVD diseases}

Healthcare is a main focus of the Saudi Vision 2030, through which the Saudi government has initiated radical changes in the structure and function of its 
healthcare system via its National Transformation Program to achieve quality care and effective service delivery. In addition, the government has already recognized the importance of the primary prevention of CVD diseases and announced four major projects aimed at improving lifestyles [72-77]. Furthermore, the World Heart Federation has undertaken an initiative to develop a series of "roadmaps" to reduce premature deaths from CVD by at least 25\% by 2025 . These roadmaps can be used as guidance for countries seeking to develop or update their national noncommunicable diseases programs for the prevention and control of these conditions [78].

\section{Limitations of the study}

Our study has some limitations. First, the sampling framework of the PURE-Saudi study was not nationally representative, necessitating caution in generalizing the findings to the whole Saudi population. Additionally, relatively healthier individuals may have enrolled in our study; however; the prevalence of CVD risk factors is similar to that of previous national surveys, strengthening our study sampling methodology and results. Second, follow-up rates of CVD events and mortality were low, likely because of the small sample size. Efforts are ongoing to expand PURE Saudi to a larger population across all areas in the country to allow for meaningful event rates in the follow-up. Lastly, we cannot exclude the role of genetic predisposition in such a high prevalence of CVD risk factors, which could be related to high consanguinity in the Saudi population. We have recently reported a high prevalence of familial hypercholesterolemia in Saudi Arabia and the other Arabian Gulf countries [79].

\section{Conclusion}

The PURE-Saudi study demonstrated that the continued high prevalence of unhealthy lifestyle and CVD risk factors in the adult Saudi population reflects a continued trend from a decade of several population surveys. Some of these factors were more prevalent in the rural than in the urban population. National awareness programs and multi-faceted healthcare policy changes are urgently needed to reduce the future burden of CVD risk and mortality.

\section{Supplementary information}

Supplementary information accompanies this paper at https://doi.org/10. 1186/s12889-020-09298-w.

Additional file 1: Additional Table 1. Risks of hyperlipidemia and

hyperglycemia among men and women.

Additional file 2: Additional Table 2. Risks of hyperlipidemia and hyperglycemia according to age.
Additional file 3: Additional Table 3. Risks of hyperlipidemia and hyperglycemia in urban and rural populations.

Additional file 4: Additional Table 4. Characteristics of the PURESaudi study vs past studies that have assessed the prevalence of cardiovascular disease risk factors in Saudi Arabia.

\section{Abbreviations}

CVD: Cardiovascular disease; PURE: Prospective Urban Rural Epidemiology; MET: Metabolic equivalent of task; PHCC: Primary healthcare center; SD: Standard deviation; IQR: Interquartile range; BMI: Body mass index; OHA: Oral hypoglycemic agent; SBP: Systolic blood pressure; DBP: Diastolic blood pressure; OPT: Occupied Palestinian Territory; UAE: United Arab Emirates; MONICA: Monitoring trends and determinants in cardiovascular disease

\section{Acknowledgements}

We thank Sumathy Rangarajan for overall coordination of the PURE study, Hani Altaradi for coordinating the PURE-Saudi study, Anhar Ullah and Shofiqul Islam for statistical analyses, and the following research assistants for data collection and quality control: Monther Abdulrahman, Rehab Nouri, Omar Alnobani, Nour Alkamel, and Mohammad Ali.

\section{Authors' contributions}

KFA and SY designed the study. KFA, HA, and MQA facilitated data gathering. $K F A, M A B, T H A$, and SR performed the data analysis and drafted the manuscript. All authors contributed to the interpretation of results and the revision of the manuscript, as well as approving the final manuscript.

\section{Funding}

The following funders supported the study in many financial aspects, including part-time research assistant salaries, expenses related to transportation of the study team and blood samples, cost of blood sample analysis, and other expenses: Saudi Heart Association, Saudi Gastroenterology Association, Dr. Mohammad Alfagih Hospital, and the Deanship of Scientific Research at King Saud University, Riyadh, Saudi Arabia (research group no RG-1436-013).

\section{Availability of data and materials}

The data are not publicly available because the participants or the ethics committees have not given permission for sharing the data publicly and the study is ongoing.

\section{Ethics approval and consent to participate}

The King Saud University Ethics Committee granted ethics approval. Participation in the study was voluntary, and all eligible participants who provided written informed consent were enrolled.

\section{Consent for publication}

Not applicable.

\section{Competing interests}

The authors certify that there is no conflict of interest with any financial organization regarding the material discussed in the manuscript. The authors declare that they have no competing interests.

\section{Author details}

${ }^{1}$ Department of Cardiac Sciences, King Fahad Cardiac Center, College of Medicine, King Saud University, Riyadh, Saudi Arabia. ${ }^{2}$ Department of Family and Community Medicine, College of Medicine, King Saud University, Riyadh, Saudi Arabia. ${ }^{3}$ Population Health Research Institute, DBCVS Research Institute, McMaster University, Hamilton, Canada.

Received: 1 January 2020 Accepted: 26 July 2020

Published online: 08 August 2020

\section{References}

1. Organization WHO. Cardiovascular diseases (CVDs) fact sheet. Geneva: WHO; 2015. Retrieved at: https://www.who.int/en/news-room/fact-sheets/detail/ cardiovascular-diseases-(cvds). Accessed 20 Jan 2016.

2. Aljefree N, Ahmed F. Prevalence of cardiovascular disease and associated risk factors among adult population in the Gulf region: a systematic review. 
Adv Public Health. 2015;2015:23. Article ID 235101. https://doi.org/10.1155/ 2015/235101.

3. Yusuf S, Hawken S, Ôunpuu S, Dans T, Avezum A, Lanas F, et al. Effect of potentially modifiable risk factors associated with myocardial infarction in 52 countries (the INTERHEART study): case-control study. Lancet. 2004; 364(9438):937-52.

4. O'Donnell MJ, Xavier D, Liu L, Zhang H, Chin SL, Rao-Melacini P, et al. Risk factors for ischaemic and intracerebral haemorrhagic stroke in 22 countries (the INTERSTROKE study): a case-control study. Lancet. 2010; 376(9735):112-23.

5. Mabry R, Reeves MM, Eakin EG, Owen N. Evidence of physical activity participation among men and women in the countries of the Gulf cooperation council: a review. Obes Rev. 2010;11(6):457-64.

6. Alotaibi A, Perry L, Gholizadeh L, Al-Ganmi A. Incidence and prevalence rates of diabetes mellitus in Saudi Arabia: an overview. J Epidemiol Glob Health. 2017;7(4):211-8.

7. Ahmed AM, Hersi A, Mashhoud W, Arafah MR, Abreu PC, Al Rowaily MA et al. Cardiovascular risk factors burden in Saudi Arabia: the Africa Middle East cardiovascular epidemiological (ACE) study. J Saudi Heart Assoc. 2017; 29(4):235-43.

8. Moradi-Lakeh M, El Bcheraoui C, Tuffaha M, Daoud F, Al Saeedi M, Basulaiman M, et al. Tobacco consumption in the Kingdom of Saudi Arabia, 2013: findings from a national survey. BMC Public Health. 2015; 15(1):611.

9. Memish ZA, El Bcheraoui C, Tuffaha M, Robinson M, Daoud F, Jaber S, et al. Peer reviewed: obesity and associated factors - Kingdom of Saudi Arabia, 2013. Prev Chronic Dis. 2014;11:140236. https://doi.org/10.5888/pcd11. 140236 PMID: 25299980.

10. El Bcheraoui C, Memish ZA, Tuffaha M, Daoud F, Robinson M, Jaber S, et al. Hypertension and its associated risk factors in the Kingdom of Saudi Arabia, 2013: a national survey. Int J Hypertens. 2014;2014:564679. https://doi.org/ 10.1155/2014/564679 PMID: 25170423.

11. Al-Nozha MM, Al-Mazrou YY, Arafah MR, Al-Maatouq MA, Khalil MZ, Khan $\mathrm{NB}$, et al. Smoking in Saudi Arabia and its relation to coronary artery disease. J Saudi Heart Assoc. 2009;21(3):169-76.

12. Al-Nozha MM, Al-Hazzaa HM, Arafah MR, Al-Khadra A, Al-Mazrou YY, AlMaatouq MA, et al. Prevalence of physical activity and inactivity among Saudis aged 30-70 years. A population-based cross-sectional study. Saudi Med J. 2007;28(4):559-68 https://pubmed.ncbi.nlm.nih.gov/17457478/. PMID: 17457478.

13. Al-Nozha MM, Al-Mazrou YY, Al-Maatouq MA, Arafah MR, Khalil MZ, Khan NB, et al. Obesity in Saudi Arabia. Saudi Med J. 2005;26(5):824-9 https:// pubmed.ncbi.nlm.nih.gov/15951877/. PMID: 15951877.

14. Al-Hamdan N, Kutbi A, Choudhry A, Nooh R, Shoukri M, Mujib S. WHO stepwise approach to NCD surveillance country-specific standard report Saudi Arabia. Ministry of Health, Kingdom of Saudi Arabia, in collaboration with World Health Organization, EMRO; 2005.

15. Al-Nozha MM, Arafah MR, Al-Mazrou YY, Al-Maatouq MA, Khan NB, Khalil MZ, et al. Coronary artery disease in Saudi Arabia. Saudi Med J. 2004;25(9): 1165-71 https://pubmed.ncbi.nlm.nih.gov/15448760/. PMID: 15448760.

16. Al-Nuaim AA, Bamgboye EA, Al-Rubeaan KA, Al-Mazrou Y. Overweight and obesity in Saudi Arabian adult population, role of sociodemographic variables. J Community Health. 1997;22(3):211-23.

17. Al-Nuaim AR. High prevalence of metabolic risk factors for cardiovascular diseases among Saudi population, aged 30-64 years. Int J Cardiol. 1997; 62(3):227-35.

18. Abalkhail BA, Shawky S, Ghabrah TM, Milaat WA. Hypercholesterolemia and 5-year risk of development of coronary heart disease among university and school workers in Jeddah, Saudi Arabia. Prev Med. 2000:31(4):390-5.

19. Hasim T. Smoking habits of students in College of Applied Medical Science, Saudi Arabia. Saudi Med J. 2000;21(1):76-80 https://pubmed.ncbi.nlm.nih. gov/11533755/. PMID: 11533755

20. Kalantan KA, Mohamed AG, Al-Taweel AA, Ghani HA. Hypertension among attendants of primary health care centers in Al-Qassim region, Saudi Arabia. Saudi Med J. 2001;22(11):960-3 https://pubmed.ncbi.nlm.nih.gov/11744965/. PMID: 11744965

21. Al-Rafaee S, Al-Hazzaa HM. Physical activity profile of adult males in Riyadh City. Saudi Med J. 2001;22(9):784-9 https://pubmed.ncbi.nIm.nih.gov/115 90453/. PMID: 11590453.

22. Al Haddad N, Al Habeeb T, Abdel Gadir M, Al Ghamdy Y, Qureshi N. Smoking patterns among primary health care attendees, Al-Qassim region,
Saudi Arabia. 2003. East Mediterr Health J. 2003;9(5-6):911-22 https:// pubmed.ncbi.nIm.nih.gov/16450521/. PMID: 16450521.

23. Al-Nozha MM, Al-Maatouq MA, Al-Mazrou YY, Al-Harthi SS. Diabetes mellitus in saudi arabia. 2004. Saudi Med. 2004;25(11):1603-10 https://pubmed.ncbi. nlm.nih.gov/15573186/. PMID: 15573186.

24. Al-Nozha MM, Abdullah M, Arafah MR, Khalil MZ, Khan NB, Al-Mazrou YY, et al. Hypertension in Saudi Arabia. Saudi Med J. 2007;28(1):77-84 https:// pubmed.ncbi.nIm.nih.gov/17206295/. PMID: 17206295.

25. Al-Nozha MM, Arafah MR, Al-Maatouq MA, Khalil MZ, Khan NB, Al-Marzouki K, et al. Hyperlipidemia in Saudi Arabia. Saudi Med J. 2008;29(2):282-7 https://pubmed.ncbi.nlm.nih.gov/18246242/. PMID: 18246242.

26. Al-Baghli NA, Al-Ghamdi AJ, Al-Turki KA, El-Zubaier AG, Al-Ameer MM, AlBaghli FA. Overweight and obesity in the eastern province of Saudi Arabia. Saudi Med J. 2008;29(9):1319-25 https://pubmed.ncbi.nlm.nih.gov/1881342 O/. PMID: 18813420.

27. Midhet F, Al Mohaimeed AR, Sharaf F. Dietary practices, physical activity and health education in Qassim region of Saudi Arabia. Int J Health Sci. 2010; 4(1):3-10 https://pubmed.ncbi.nlm.nih.gov/21475520/. PMID: 21475520.

28. El Bcheraoui C, Basulaiman M, Tuffaha M, Daoud F, Robinson M, Jaber S, et al. Status of the diabetes epidemic in the Kingdom of Saudi Arabia, 2013. Int J Public Health. 2014;59(6):1011-21.

29. Basulaiman M, El Bcheraoui C, Tuffaha M, Robinson M, Daoud F, Jaber S, et al. Hypercholesterolemia and its associated risk factors-Kingdom of Saudi Arabia, 2013. Ann Epidemiol. 2014;24(11):801-8.

30. Al-Rubeaan K, Al-Manaa HA, Khoja TA, Ahmad NA, Al-Sharqawi AH, Siddiqui $\mathrm{K}$, et al. Epidemiology of abnormal glucose metabolism in a country facing its epidemic: SAUDI-DM study. J Diabetes. 2015;7(5):622-32.

31. Alzeidan R, Rabiee F, Mandil A, Hersi A, Fayed A. Non-communicable disease risk factors among employees and their families of a Saudi university: an epidemiological study. PLoS One. 2016;11(11):e0165036.

32. Alharthi FS, Alrahimi JS, Alotaibi AA, Alhamdi DA, Ibrahim BM, Badeeb YA. Prevalence of undiagnosed cardiovascular risk factors in adults aged 20-40: a cross-sectional study in 2016 in Jeddah, Saudi Arabia. Cardiol Res. 2017; 8(3):111.

33. Teo K, Chow CK, Vaz M, Rangarajan S, Yusuf S. The Prospective Urban Rural Epidemiology (PURE) study: examining the impact of societal influences on chronic noncommunicable diseases in low-, middle-, and high-income countries. Am Heart J. 2009;158(1):1-7.e1. https://doi.org/10.1016/j.ahj.2009. 04.019 PMID: 19540385.

34. Corsi DJ, Subramanian S, Chow CK, McKee M, Chifamba J, Dagenais G, et al. Prospective Urban Rural Epidemiology (PURE) study: baseline characteristics of the household sample and comparative analyses with national data in 17 countries. Am Heart J. 2013;166(4):636-646.e4. https://doi.org/10.1016/j.ahj. 2013.04.019 PMID: 24093842.

35. Yusuf S, Rangarajan S, Teo K, Islam S, Li W, Liu L, et al. Cardiovascular risk and events in 17 low-, middle-, and high-income countries. N Engl J Med. 2014;371(9):818-27.

36. Miller V, Mente A, Dehghan M, Rangarajan S, Zhang X, Swaminathan S, et al. Fruit, vegetable, and legume intake, and cardiovascular disease and deaths in 18 countries (PURE): a prospective cohort study. Lancet. 2017;390(10107): 2037-49. https://doi.org/10.1016/s0140-6736(17)32253-5 PMID: 28864331.

37. Chiuve SE, Fung TT, Rimm EB, Hu FB, McCullough ML, Wang M, et al. Alternative dietary indices both strongly predict risk of chronic disease. J Nutr. 2012;142(6):1009-18.

38. McCullough ML, Willett WC. Evaluating adherence to recommended diets in adults: the alternate healthy eating index. Public Health Nutr. 2006;9(1a): $152-7$.

39. McGorrian C, Yusuf S, Islam S, Jung H, Rangarajan S, Avezum A, et al. Estimating modifiable coronary heart disease risk in multiple regions of the world: the INTERHEART modifiable risk score. Eur Heart J. 2011;32(5): 581-9.

40. Craig $C L$, Marshall $A L$, Sjöström M, Bauman $A E$, Booth $M L$, Ainsworth $B E$, et al. International physical activity questionnaire: 12-country reliability and validity. Med Sci Sports Exerc. 2003;35(8):1381-95.

41. El Bcheraoui C, Basulaiman M, AlMazroa MA, Tuffaha M, Daoud F, Wilson S, et al. Fruit and vegetable consumption among adults in Saudi Arabia, 2013. Nutr Diet Suppl. 2015;2015(1):41-9. https://doi.org/10.2147/NDS.S77460.

42. AlHabib KF, Elasfar AA, Alfaleh $\mathrm{H}$, Kashour T, Hersi A, AlBackr H, et al. Clinical features, management, and short-and long-term outcomes of patients with acute decompensated heart failure: phase I results of the HEARTS database. Eur J Heart Fail. 2014;16(4):461-9. 
43. AlHabib KF, Hersi A, AlFaleh H, AlNemer K, AlSaif S, Taraben A, et al. Baseline characteristics, management practices, and in-hospital outcomes of patients with acute coronary syndromes: results of the Saudi project for assessment of coronary events (SPACE) registry. J Saudi Heart Assoc. 2011;23(4):233-9.

44. Alhabib KF, Kinsara AJ, Alghamdi S, Al-Murayeh M, Hussein GA, AlSaif S, et al. The first survey of the Saudi acute myocardial infarction registry program: Main results and long-term outcomes (STARS-1 program). PLoS One. 2019;14(5):e0216551.

45. Roper NA, Bilous RW, Kelly WF, Unwin NC, Connolly VM. Cause-specific mortality in a population with diabetes: South Tees diabetes mortality study. Diabetes Care. 2002;25(1):43-8

46. Cho N, Kirigia J, Mbanya J, Ogurstova K, Guariguata L, Rathmann W. IDF diabetes atlas-eighth: The International Diabetes Federation; 2017. http:// fmdiabetes.org/wp-content/uploads/2018/03/IDF-2017.pdf.

47. Dagenais GR, Gerstein HC, Zhang X, McQueen M, Lear S, Lopez-Jaramillo P, et al. Variations in diabetes prevalence in low-, middle-, and high-income countries: results from the prospective urban and rural epidemiological study. Diabetes Care. 2016;39(5):780-7.

48. Chow CK, Teo KK, Rangarajan S, Islam S, Gupta R, Avezum A, et al. Prevalence, awareness, treatment, and control of hypertension in rural and urban communities in high-, middle-, and low-income countries. Jama. 2013;310(9):959-68.

49. Yusufali AM, Khatib R, Islam S, Alhabib KF, Bahonar A, Swidan HM, et al. Prevalence, awareness, treatment and control of hypertension in four Middle East countries. J Hypertens. 2017;35(7):1457-64.

50. Attaei MW, Khatib R, McKee M, Lear S, Dagenais G, lgumbor EU, et al. Availability and affordability of blood pressure-lowering medicines and the effect on blood pressure control in high-income, middle-income, and lowincome countries: an analysis of the PURE study data. Lancet Public Health. 2017;2(9):e411-e9.

51. Al-Saleem SA, Al-Shahrani A, Al-Khaldi YM. Hypertension care in Aseer region, Saudi Arabia: barriers and solutions. Saudi J Kidney Dis Transpl. 2014; 25(6):1328.

52. Khatib R, Schwalm J-D, Yusuf S, Haynes RB, McKee M, Khan M, et al. Patient and healthcare provider barriers to hypertension awareness, treatment and follow up: a systematic review and meta-analysis of qualitative and quantitative studies. PLoS One. 2014;9(1):e84238.

53. El Bcheraoui C, Tuffaha M, Daoud F, Kravitz H, AlMazroa MA, Al Saeedi M, et al. Access and barriers to healthcare in the Kingdom of Saudi Arabia, 2013: findings from a national multistage survey. BMJ Open. 2015;5(6): e007801.

54. Al-Gelban KS, Khan MY, Al-Khaldi YM, Mahfouz AA, Abdelmoneim I, Daffalla A, et al. Adherence of primary health care physicians to hypertension management guidelines in the Aseer region of Saudi Arabia. Saudi J Kidney Dis Transpl. 2011;22(5):941-8 https://pubmed.ncbi.nlm.nih.gov/21912023/. PMID: 21912023

55. Al-Quwaidhi A, Pearce M, Critchley J, Sobngwi E, O'Flaherty M. Trends and future projections of the prevalence of adult obesity in Saudi Arabia, 19922022. East Mediterr Health J. 2014;20(10):589-95.

56. Food balance sheet SA. FAOSTAT [Internet]. Rome: Food and Agriculture Organization of the United Nations http://faostat.fao.org/site/368/default. aspx\#ancor, Accessed 20 July 2014.

57. Siddiqui MA, Khan MF, Carline TE. Gender differences in living with diabetes mellitus. Mater Sociomed. 2013;25(2):140.

58. Albargawi M, Snethen J, Gannass AA, Kelber S. Perception of persons with type 2 diabetes mellitus in Saudi Arabia. Int J Nurs Sci. 2016;3(1):39-44.

59. Kulshreshtha A, Goyal A, Dabhadkar K, Veledar E, Vaccarino V. Urban-rural differences in coronary heart disease mortality in the United States: 1999_ 2009. Public Health Rep. 2014;129(1):19-29.

60. Popkin BM. Global nutrition dynamics: the world is shifting rapidly toward a diet linked with noncommunicable diseases-. Am J Clin Nutr 2006;84(2): 289-298.

61. Ng SW, Popkin BM. Time use and physical activity: a shift away from movement across the globe. Obes Rev. 2012;13(8):659-80.

62. Ng SW, Norton EC, Popkin BM. Why have physical activity levels declined among Chinese adults? Findings from the 1991-2006 China health and nutrition surveys. Soc Sci Med. 2009;68(7):1305-14.

63. Collaboration NRF. Rising rural body-mass index is the main driver of the global obesity epidemic in adults. Nature. 2019;569(7755):260.

64. Ettarh $R$, Van de Vijver S, Oti S, Kyobutungi C. Peer reviewed: overweight, obesity, and perception of body image among slum residents in Nairobi,
Kenya, 2008-2009. Prev Chronic Dis. 2013;10:E212. https://doi.org/10.5888/ pcd10.130198 PMID: 24355105.

65. Almalki M, FitzGerald G, Clark M. Health care system in Saudi Arabia: an overview. East Mediterr Health J. 2012;18(10):1078-9. https://doi.org/10. 26719/2012.18.10.1078 National transformation program. PMID: 23301365.

66. $\mathrm{Ng} \mathrm{N}$, Johnson $\mathrm{O}$, Lindahl B, Norberg M. A reversal of decreasing trends in population cholesterol levels in Västerbotten County, Sweden. Glob Health Action. 2012;5(1):10367.

67. Rosengren A, Smyth A, Rangarajan S, Ramasundarahettige C, Bangdiwala SI, AlHabib KF, et al. Socioeconomic status and risk of cardiovascular disease in 20 low-income, middle-income, and high-income countries: the prospective urban rural epidemiologic (PURE) study. Lancet Glob Health. 2019;7:e748-60.

68. Lindroth $M$, Lundqvist $\mathrm{R}$, Lilja M, Eliasson M. Cardiovascular risk factors differ between rural and urban Sweden: the 2009 northern Sweden MONICA cohort. BMC Public Health. 2014;14(1):825.

69. Afshin A, Sur PJ, Fay KA, Cornaby L, Ferrara G, Salama JS, et al. Health effects of dietary risks in 195 countries, 1990-2017: a systematic analysis for the Global Burden of Disease Study 2017. Lancet. 2019;393:1958-72.

70. Srivastava K. Urbanization and mental health. Ind Psychiatry J. 2009;18(2):75.

71. Caracci G, Mezzich JE. Culture and urban mental health. Psychiatr Clin N Am. 2001;24(3):581-93.

72. Arabia. TgoS. National transformation program. 2016. https://vision2030.gov. sa/en/programs/NTP.

73. Alharbi MF. An analysis of the Saudi health-care system's readiness to change in the context of the Saudi National Health-care Plan in vision 2030. Int J Health Sci. 2018;12(3):83-7 https://pubmed.ncbi.nlm.nih.gov/29896076/. PMID: 29896076

74. King Salman Park. The King Salman Park Project 2019, Available from: http:// riyadhksp.sa/en/.

75. Green Riyadh. The Green Riyadh Project 2019, Available from: http://www. riyadhgreen.sa/en/.

76. Sport Boulevard. The Sport Boulevard Project 2019, Available from: http:// www.riyadhalmasar.sa/en/.

77. Riyadh Art. The Riyadh Art Project 2019, Available from: http://www. riyadhart.sa/en/.

78. WHF. World Heart Federation Roadmaps Geneva. Available at: http// wuw.worldheart-federation.org/what-we-do/whf-roadmaps/. Accessed 25 May 2016.

79. Al-Rasadi K, Alhabib KF, Al-Allaf F, Al-Waili K, Al-Zakwani I, AlSarraf A, et al. The Gulf Familial Hypercholesterolemia Registry (Gulf FH): Design, Rationale and Preliminary Results. Curr Vasc Pharmacol. 2020;18(1):57-64. https://doi. org/10.2174/1570161116666181005125459. PMID: 30289081.

\section{Publisher's Note}

Springer Nature remains neutral with regard to jurisdictional claims in published maps and institutional affiliations.

Ready to submit your research? Choose BMC and benefit from

- fast, convenient online submission

- thorough peer review by experienced researchers in your field

- rapid publication on acceptance

- support for research data, including large and complex data types

- gold Open Access which fosters wider collaboration and increased citations

- maximum visibility for your research: over $100 \mathrm{M}$ website views per year

At BMC, research is always in progress.

Learn more biomedcentral.com/submission 